\title{
Applying rigour to the interpretation of surgical site infection rates
}

\author{
Victoria Williams, ${ }^{1}$ Jerome A Leis ${ }^{1,2,3}$
}

\begin{abstract}
${ }^{1}$ Infection Prevention \& Control, Sunnybrook Health Sciences Centre, Toronto, Ontario,

Canada

${ }^{2}$ Division of Infectious Diseases, Sunnybrook Health Sciences Centre, Toronto, Ontario, Canada

${ }^{3}$ Department of Medicine and Centre for Quality Improvement and Patient Safety, University of Toronto, Toronto, Ontario, Canada
\end{abstract}

\section{Correspondence to}

Dr Jerome A Leis, Sunnybrook Health Sciences Centre, Toronto, Canada;

jerome.Leis@sunnybrook.ca

Accepted 4 December 2019 Published Online First

13 December 2019

\section{SLinked}

- http://dx.doi.org/10.1136/ bmjgs-2018-008976

- http://dx.doi.org/10.1136/ bmjqs-2019-010586

\section{Check for updates}

(C) Author(s) (or their employer(s)) 2020. No commercial re-use. See rights and permissions. Published by BMJ.

To cite: Williams V, Leis JA. BMJ Qual Saf

2020:29:446-448.
Surgical site infection (SSI) rates are closely scrutinised by hospital committees seeking to identify opportunities to prevent these important complications. In most hospitals, SSI rates are displayed as a monthly or quarterly incidence using a bar or line graph with comparison with the hospital's historical rate or some external benchmark.

The response to these data is usually dichotomous. Hospital committee members may make congratulatory statements if the incidence is decreasing, or alternatively express concern that action is needed if there is an upward trend. Some hospitals even formalise these reactions with red-amber-green designations, ignoring chance variation. ${ }^{12}$ It is striking that in clinical research we would never automatically accept any difference as being significant without demanding a more rigorous statistical analysis. Yet, when it comes to quality improvement, the direction of the change alone is often enough to generate assertive conclusions about the state of a hospital's infection rates.

The challenge in the interpretation of SSI surveillance data has been to identify a method that can accurately discern a significant change in rates from the normal variation that is best acknowledged as being unchanged. Statistical process control (SPC) is increasingly used across healthcare to assist in answering this question. ${ }^{3}$ This method for measuring changes over time was originally used by Walter Shewhart, an American engineer, who first introduced it to the world of manufacturing in the 1920s. He was hired to improve the quality of telephone hardware, and observed that when the variation in production parameters was high the quality suffered. He became interested in using data to track performance over time using control charts (sometimes referred to as Shewhart charts in his honour), to prospectively ensure that parameters fell within the expected 'chance-cause' variation. ${ }^{4}$ Any deviation from this would prompt an assessment into possible causes for this change from a quality production standpoint. Applying this approach to infection surveillance allows easy differentiation between 'common cause' (random, natural) and 'special cause' (unnatural) variation, thus allowing hospitals to focus on variations that are potentially preventable through control efforts while avoiding a premature response to random increases that cannot be controlled. ${ }^{56}$

Control charts are not new to quality improvement in healthcare, and many institutions including our own have used them routinely to measure improvement. $^{7-9}$ But not all SPC charts are the same and the parameters used can greatly influence their performance characteristics. The most common settings used to measure SSI rates are U-charts and P-charts, which provide the number of SSIs per monthly surgical cases or per cent SSIs, respectively. Control limits are typically set to three-sigma (equivalent to $3 \mathrm{SD}$ ), where consecutive points above or below the lower control limits represent a significant change equivalent to $\mathrm{p}<0.01$. $^{10}$ In practice, however, this approach has generally proven to be insensitive in detecting potentially important changes in SSI rates. For example, figure $1 \mathrm{~A}$ displays a U-chart of the cardiac SSI rates at our institution over the past decade which fall nearly completely within common cause variation. Some authors have argued that risk-adjusted charts based on the standardised infection ratio improves sensitivity of standard control charts, ${ }^{6}$ but there is no accepted method for using SPC in SSI surveillance, leading to significant variation in practice.

In the current issue, Ilieş et al ${ }^{11}$ sought to identify the optimal use of SPC for SSI 


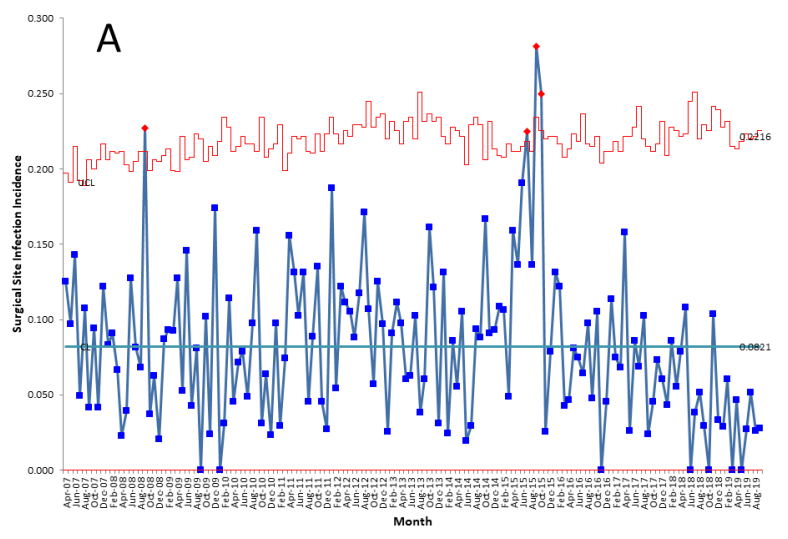

SPC chart types including the traditional P-chart, the moving average (MA) chart, as well as the exponentially weighted MA chart. Each month that generated a statistically significant signal in at least one chart $(n=2709)$ was reviewed by three independent epidemiologists to score the clinical significance of the change. These epidemiologists were able to use clinical information including infection type, infecting organism and surgeon, but were blinded to the chart type and parameters set to trigger each signal.

Their results determined that the best balance between sensitivity and specificity was achieved using a combination of two of the MA charts set at one-sigma control limits. The first MA chart had a 12-month span, 18-month baseline period and 6-month lag and used an external benchmark as the baseline. The second had a 6-month span, 3-month baseline period and a 3-month lag based on individual hospital data. Together the two charts were able to detect small sustained increases in SSIs as compared with external benchmarks as well as large, short-duration increases compared with the hospital's historical performance, with a sensitivity of 0.90 and a specificity of 0.67 .

What does this mean in practice? For those who have used SPC charts to measure improvement, relying on one-sigma control limits represents a significant 'shift'. The traditional application of SPC has used three-sigma control limits to ensure that any signal represents a statistically significant change. But the goal is different in infection surveillance. SPC provides a mechanism to identify potentially relevant signals in SSI rates that should prompt an investigation to determine if there are preventable factors that need to be addressed. In other words, the prospective use of these MA charts can be a safety mechanism resembling Shewhart's original use of SPC: to rapidly identify and address any parameters that could indicate a problem.

While the method proposed by Ilies and colleagues ${ }^{11}$ carries considerable promise for standardising SPC methodology used for SSI surveillance, some questions require answering before calling for widespread adoption of this approach. The performance characteristics were derived from SSI data generated from the Duke Infection Control Outreach Network, a large network of American community hospitals, but further validation across other healthcare settings is needed. Wider spread adoption of SPC methodology for SSI surveillance will also require improved knowledge and accessibility of SPC software by infection prevention teams and hospital epidemiologists. Some experts have created an open source database with an automated SPC chart generator that can be used by facilities to easily create control charts using their own surveillance data. ${ }^{12}$

We incorporated our cardiac SSI surveillance data into the MA charts recommended by Ilieş et al and found that the increase in SSI rates noted in 2015 using our U-chart could have been detected 2 months 
earlier using this method (figure 1B,C). An additional signal was identified in January 2012 that, using traditional surveillance, did not register as significant on the U-chart and was only noted anecdotally during a cardiac surgery SSI meeting 5 months later. Our experience suggests that this method would have allowed earlier intervention on these occasions, but a prospective evaluation is needed. And, in fact, a multicentre, randomised controlled trial is under way to confirm whether traditional SSI surveillance can be augmented using this approach. ${ }^{13}$

Increased emphasis has been placed on public reporting and benchmarking of healthcare-associated infection in recent years, but ensuring a standardised approach between institutions remains a challenge. ${ }^{14}$ SPC methods have always offered a robust method for identifying true signals amidst the noise of random variation. But the approach employed by Ilieş and colleagues offers a promising new method for earlier detection of signals worth investigating. Future standards for SSI surveillance will likely incorporate this method for analysing and interpreting temporal trends.

Correction notice The article has been corrected since it published onlie first. The middle initial of the co-author was missing which has been amended to Jerome A Leis.

Contributors Both authors contributed to the preparation of this manuscript.

Funding The authors have not declared a specific grant for this research from any funding agency in the public, commercial or not-for-profit sectors.

Competing interests None declared.

Patient consent for publication Not required.

Provenance and peer review Commissioned; internally peer reviewed.

\section{REFERENCES}

1 Anhøj J, Hellesøe A-MB. The problem with red, amber, green: the need to avoid distraction by random variation in organisational performance measures. BMJ Qual Saf 2017;26:81-4.

2 Schmidtke KA, Poots AJ, Carpio J, et al. Considering chance in quality and safety performance measures: an analysis of performance reports by boards in English NHS trusts. BMJ Qual Saf 2017;26:61-9.

3 Benneyan JC, Lloyd RC, Plsek PE. Statistical process control as a tool for research and healthcare improvement. Qual Saf Health Care 2003;12:458-64.

4 Shewhart WA. Control of quality of manufactured product (Reprinted by the American Society for quality control, 1980). New York: D. Van Nostrand Company, 1931.

5 Benneyan JC. Statistical quality control methods in infection control and hospital epidemiology, part I: introduction and basic theory. Infect Control Hosp Epidemiol 1998;19:194-214.

6 Gustafson TL. Practical risk-adjusted quality control charts for infection control. Am J Infect Control 2000;28:406-14.

7 Sadeghi M, Leis JA, Laflamme C, et al. Standardisation of perioperative urinary catheter use to reduce postsurgical urinary tract infection: an interrupted time series study. BMJ Qual Saf 2019;28:32-8.

8 Lamb MJ, Baillie L, Pajak D, et al. Elimination of screening urine cultures prior to elective joint arthroplasty. Clin Infect Dis 2017;64:806-9.

9 Kirkland KB, Homa KA, Lasky RA, et al. Impact of a hospital-wide hand hygiene initiative on healthcare-associated infections: results of an interrupted time series. BMJ Qual Saf 2012;21:1019-26.

10 Provost LR, Murray SK. The health care data guide: learning from data for improvement. 1st ed. San Francisco, CA: JosseyBass, 2011.

11 Ilieş I, Anderson DJ, Salem J, et al. Large-Scale empirical optimisation of statistical control charts to detect clinically relevant increases in surgical site infection rates. BMJ Qual Saf 2020:472-81.

12 Wiemken TL, Furmanek SP, Carrico RM, et al. Process control charts in infection prevention: make it simple to make it happen. Am J Infect Control 2017;45:216-21.

13 ClinicalTrials.gov [Internet]. Bethesda (MD): National library of medicine (US). identifier NCT03075813, early recognition and response to increases in surgical site infections using optimized statistical process control charts: the early 2RIS study (early 2RIS), 2017. Available: https:// clinicaltrials.gov/ct2/show/NCT03075813 [Accessed 22 Nov 2019].

14 Talbot TRet al. Public reporting of health Care-Associated surveillance data: recommendations from the healthcare infection control practices Advisory Committee. Ann Intern Med 2013;159:631-5. 